\section{Universidade e economia solidária: algumas considerações sobre processos de fomento e políticas públicas em economia solidária}

\author{
Wagner Molina \\ Docente investigador de la Universidad \\ Federal de San Carlos, UFSCar. Brasil \\ Coordinador del Centro Multidisciplinar \\ Integrado de Investigación, Formación \\ e Intervención en Economía Solidaria \\ (Numi-ECOSOL) UFSCar
}

\section{Ana Lucia Cortegoso}

Docente investigadora de la

UFSCar. Brasil

Miembro del Numi-ECOSOL, UFSCar.
Economía Social y Solidaria /

Intervenciones

RECEPCIÓN: 26/06/15

ACEPTACIÓN FINAL: 25/08/15

\section{Resumo}

Este texto foi construído tendo como base experiências e reflexões sobre processos de incubação de empreendimentos e iniciativas econômicas de trabalho associado e sobre políticas públicas no campo da Economia Solidária (ES) a partir da atuação de um núcleo universitário de ensino, pesquisa e extensão em ES sucessor de uma incubadora tecnológica de cooperativas populares. No que se refere ao processo de incubação, além de apresentar e examinar aspectos do método de incubação que vem sendo construído pela equipe, são indicadas outras formas de fomento à economia solidária sendo desenvolvidas ou identificadas como relevantes para esta finalidade. Em relação às políticas públicas, além de um panorama da situação atual em relação à ES, são indicadas e examinadas lacunas e dificuldades referentes à formulação e implementação de políticas públicas neste e para este campo.

\section{Resumen}

Este texto fue construido teniendo como base experiencias y reflexiones sobre los procesos de incubación de emprendimientos e iniciativas económicas de trabajo asociado y sobre políticas públicas en el campo de la economía solidaria a partir de la acción de un núcleo universitario de la docencia, investigación y extensión en Economía Solidaria (ES) sucesor de una incubadora tecnológica de cooperativas populares. Con referencia al proceso de incubación, además de presentar y examinar aspectos del método de incubación que viene siendo construido por el equipo, se indican otras formas de fomento a la ES desarrolladas o identificadas como relevantes para esta finalidad. Con relación a las políticas públicas, se presenta un panorama de la situación actual de la ES, se comentan y examinan lagunas y dificultades en cuanto a la formulación e implementación de políticas públicas en ese y para ese campo.

Palabras-clave

- economia solidaria

- incubación

- universidad

- políticas públicas en Brasil
Para citación de este artículo

Molina, W. y Cortegoso, A. L. (2015). Universidade e economia solidária: algumas considerações sobre processos de fomento e políticas públicas em economia solidária. En Revista +E versión digital, (5), pp. 158-167. Santa Fe, Argentina: Ediciones UNL. 


\section{G6 \\ a INCOOP surgiu tendo como \\ centralidade de suas ações \\ os processos de incubação \\ de empreendimentos \\ econômicos solidários}

\section{Ações de fomento a partir de incubadoras universitárias no campo da Economia Solidária}

O surgimento, crescimento e atuação das chamadas incubadoras universitárias no âmbito da ES foram e são amplamente relatados e examinados como parte do processo de produção e sistematização de conhecimento neste campo de atividade humana (Albuquerque, 2011, entre muitos outros). Para efeito deste texto, contudo, parece suficiente destacar como pioneira a iniciativa da COPPE/UFRJ (Bocayuva, 2001, entre outros), a partir da qual, na década de 1990, com o apoio do PRONINC ou na expectativa deste apoio, surgiram outras similares, entre elas a Incubadora Regional de Cooperativas Populares (INCOOP), na Universidade Federal de São Carlos, São Paulo, Brasil. Algumas dezenas destas entidades, espalhadas em universidades de todo o país, se estruturam em duas redes, que compartilham o papel de agentes de fomento à ES no contexto acadêmico - ou a partir dele -, embora com identidades próprias. A INCOOP surgiu, tal como muitas outras destas incubadoras, na condição de um programa de extensão, tendo como centralidade de suas ações os processos de incubação de empreendimentos econômicos solidários, compreendidos como assessoria à população para esta finalidade, conforme esta prática é definida no Anexo I da Portaria GR NO. 220/93, atualizada pela Portaria 664/99 (UFSCar, 1999/1993):

"XIII-Assessoria: oferta de subsídios através de um processo de acompanhamento de tomada de decisão na realização de trabalhos, intervenções, etc. Na assessoria há um envolvimento com todas as etapas do trabalho, incluindo avaliação de resultados."

A despeito de ter mantido sua condição de projeto de extensão até o ano de 2011, as atividades desenvolvidas no âmbito da INCOOP estiveram permanentemente orientadas pelo compromisso institucional de articulação das atividades de ensino, pesquisa e extensão em relação à economia solidária, como fenômeno de interesse. $\mathrm{O}$ envolvimento da equipe com atividades de ensino (por meio de oferta de disciplina de graduação a alunos de todos os cursos do campus São Carlos e de vagas de estágio e para desenvolvimento de monografias e trabalhos de conclusão por estudantes de diferentes cursos de graduação, orientação de dissertações e teses, e elaboração de projeto de curso de graduação) e de pesquisa (por meio de diferentes estratégias de produção e sistematização de conhecimento, publicadas em diferentes formatos), além das de extensão, sustentou o pedido de constituição de um núcleo de ensino, pesquisa e extensão em relação à economia solidária, submetido ao Conselho Universitário e aprovado em agosto de 2011, que deu origem ao Núcleo Multidisciplinar e Integrado de Estudos, Formação e Intervenção em Economia Solidária (NuMl-EcoSol), implantado a partir de 2012. A INCOOP e o NuMI, como seu sucessor, atuaram em processos de incubação de Empreendimentos Econômicos Solidários (EES) relativos a diferentes atividades econômicas, em áreas urbanas e rurais, em diferentes municípios do estado de São Paulo. A partir de 2004, a equipe sistematizou o seu método de incubação como referência para este tipo de atividade, e permanece avaliando e ajustando este método a partir dos resultados obtidos no atendimento à sociedade, particularmente àqueles segmentos mais penalizados pela organização econômica hegemônica, geradora de desigualdades sociais e desastres ambientais que já não colocam em risco apenas as gerações futuras, mas as atuais. Incubar significa, no âmbito da INCOOP (e seu sucessor), que diante de demandas apresentadas à equipe ou identificadas por esta, e considerando as condições existentes para desenvolver este tipo de atividade em cada momento específico, a equipe deve assessorar grupos para formação de EES, por meio da oferta de subsídios e de acompanhamento do processo de tomada de decisão e implementação de atividades, com participação dos responsáveis pela incubação em todas as etapas do trabalho, incluindo avaliação de resultados, por meio de relações dialógicas), de modo a alcançar, como resultado de sua atuação: existência e consolidação de empreendimentos solidários e autogestionários 
incubar significa alcançar existência e

consolidação de empreendimentos solidários

e autogestionários de natureza popular, organizados para o trabalho coletivo, que funcionem de forma autônoma, com capacidade para identificar suas próprias de natureza popular, organizados para o trabalho coletivo, que funcionem de forma autônoma, com capacidade para identificar suas próprias necessidades e providenciar para que sejam atendidas, inseridos no mercado e no contexto mais amplo da ES e com características gradualmente mais compatíveis com princípios de ES (Cortegoso et al., 2012).

A descrição inicial do método de incubação que serve como referência à equipe do NuMl indicava 16 diferentes tipos de ações coletivas identificadas como relevantes para garantir condições para que a população que constitui foco da ação da incubadora possa constituir e implementar EES. Sucessivas revisões do método, subsidiadas por resultados alcançados nos processos de incubação conduzidos pela equipe INCOOP ou por suas congêneres, pelo avanço do conhecimento produzido em muitos contextos (acadêmico entre outros, mas não apenas), a partir da evolução da economia solidária como movimento social constituído por muitos e diferentes tipos de atores sociais, foram responsáveis por ampliar este conjunto de ações para 22, conforme versão mais atual (Cortegoso e Pompermaier, no prelo) - mas já em discussão pela equipe e sujeita a novas alterações. São elas:

1) processar demandas para incubação de empreendimentos solidários.;

2) identificar população em potencial para formação de empreendimento solidário;

3) caracterizar diferentes envolvidos no processo de incubação;

4) apresentar ES como possibilidade de organização para geração de trabalho e renda, Incoop/NuMl e sua proposta de trabalho; 5) apoiar a organização inicial do grupo para tomada de decisões a respeito de formação de empreendimento solidário e suas características gerais;

6) elaborar proposta de trabalho, em conjunto com participantes do grupo a ser incubado;

7) assessorar o grupo para escolha de atividade econômica;
8) promover formação contínua e permanente de todos os membros do grupo em ES de todas as maneiras possíveis;

9) promover formação contínua e permanente de todos os membros do grupo para autogestão;

10) promover condições para capacitação técnica contínua e permanente de todos os membros do empreendimento para o serviço/produção ofertado pelo empreendimento;

11) promover elaboração participativa de normas de funcionamento do empreendimento;

12) assessorar grupo para legalização do empreendimento;

13) assessorar grupo para implantação do empreendimento;

14) assessorar grupo para implantação de sistema de monitoramento por meio de indicadores;

15) assessorar grupo esporadicamente para implementação do empreendimento;

16) assessorar grupo para participação em redes de cooperação e em iniciativas do movimento de ES;

17) assessorar o grupo incubado para lidar com processos de produção e uso de conhecimento e tecnologia;

18) assessorar o grupo para construir e manter parcerias;

19) promover condições favorecedoras para que agentes e agências sociais estabeleçam parcerias com estes empreendimentos e iniciativas;

20) assessorar empreendimentos para a adoção de práticas de consumo ético, solidário e responsável;

21) assessorar empreendimentos para comercializar seus produtos e serviços;

22) assessorar empreendimentos para planejar e aplicar estratégias de divulgação.

As ações indicadas no método de incubação do NuMI como referência para o processo representam tanto as que de fato têm sido implementadas em processos de incubação, quanto algumas 
que, a despeito de não terem ainda ocorrido em um determinado momento, são percebidas como relevantes para alcançar os resultados pretendidos para estes processos.

Os mais de 15 anos de existência do NuMI-EcoSol possibilitaram - e em muitos casos demandaram - que a equipe se envolvesse não apenas com processos de incubação, ainda que este tenha sido sempre a centralidade de sua atuação, mas com situações que consolidaram seu papel tanto como unidade acadêmica em uma universidade pública e, portanto, comprometida com atividades de ensino, pesquisa e extensão desenvolvidas de forma articulada, quanto como agente de fomento inserido no movimento mais amplo da economia solidária. Reconstruindo-se permanentemente, em termos de organização interna e estratégias de ação, o NuMI tem atuado em consonância com necessidades sociais que tem sido capaz de identificar e reconhecer como pertinente ao campo da ES, assim como aquelas estabelecidas pelo movimento ou por atores significativos deste movimento, desde que compatíveis com seus objetivos próprios e condições acessíveis. Neste sentido, como suporte para mais um seminário interno da equipe, circunstância em que esta promove avaliação sistêmica de sua atuação e estabelece diretrizes, metas e estratégias para atuação futura, foi possível identificar, além da própria incubação, e considerando atividades já realizadas (em sua maioria) e necessidades que devem merecer a atenção da equipe, um conjunto de ações de fomento à ES, tais como:

- consultoria a atores sociais diversos em relação a ES;

- promoção de práticas de comercialização e de consumo solidário;

- interlocução com instâncias de cunho político da economia solidária;

- fomento à constituição de redes e parcerias;

- promoção de melhoria em qualidade de vida da população da economia solidária em diferentes dimensões;

- inclusão social pelo trabalho de populações em particular desvantagem social;

- divulgação da ES para diferentes populações;

- melhorias no funcionamento da universidade e suas formas de ação;

- promoção de políticas públicas de interesse para a ES;

- captação de recursos para a ES;

- prospecção de novas iniciativas e empreendimentos em ES;

- promoção de Desenvolvimento de Territórios;

- ampliação de agentes de fomento à ES;

- promoção de finanças solidárias.

Além destas ações, identificadas a partir da centralidade da intervenção na realidade mas que devem garantir articulação com pesquisa e com ensino, foram identificadas, especificamente no caso da Formação em Economia Solidária, ações relativas ao ensino formal universitário, à formação da equipe e à população não acadêmica em geral. Neste sentido, estão em discussão não apenas aquelas que o NuMl já implementa (disciplina optativa de graduação, elaboração de projeto de curso de graduação, supervisão de estágio e orientação de trabalhos de pesquisa de graduação e pós-graduação, curso de especialização, apoio a curso de mestrado em universidade argentina, seleção, inserção e formação de alunos de graduação participantes de projetos do NuMl, eventos de divulgação, formação de agentes de fomento à economia solidária), quanto aquelas que fazem parte dos compromissos históricos do NuMl, tais como curso de pós-graduação stricto sensu em economia solidária e formação continuada da equipe (NuMl-EcoSol, 2010).

Este conjunto de ações está em discussão pela equipe, tanto no sentido de melhor compreender a que corresponde cada um destes tipos de ações quanto, no caso de serem confirmadas pela equipe como pertinentes ao escopo do NuMl, para identificar as condições necessárias à sua implementação, dentre as quais os responsáveis por elas. Desta discussão devem decorrer, ainda, subsídios para a revisão da organização do NuMl em relação a quais devem ser, neste momento, as Linhas de Ação a serem constituídas, mantidas ou extintas, em função das definições sobre ações e estratégias do Núcleo para a continuidade do trabalho da equipe.

A equipe do NuMl tem encontrado dificuldades, nos últimos anos, para implementar processos de incubação, tais como a de localizar pessoas da população de referência para este tipo de ação dispostas a compor novos empreendimentos solidários ou mesmo de participar de empreendimentos existentes. Desta forma, ainda que venham sendo feitos esforços para sensibilizar pessoas para a ES e realizada prospecção de produtos e serviços que poderiam ser oferecidos por empreendimentos de trabalho coletivo (a partir de atividades já em andamento, análise de cadeias produtivas, levantamento de necessidades sociais e potencialidades territoriais e exame de conhecimento produzido a partir dos centros de pesquisa no município indicativo de novas possíveis atividades produtivas, etc.), não tem sido possível iniciar novos processos de incubação. Novos empreendimentos têm surgido, contudo, envolvendo a população universitária, em particular aquela que compõe ou já compôs a equipe do NuMI, o que tem fortalecido a decisão da equipe de diversificar suas ações de fomento, de modo a ampliar a oferta de produtos e serviços baseados em princípios da ES, ampliar o conjunto de consumidores dispostos e atendidos desta forma e promover um contexto social mais amigável e favorável às iniciativas neste campo. Permanece, contudo, a perspectiva de que estas iniciativas possam, direta ou indiretamente, alcançar e inserir a população mais precarizada no município no campo da ES, bem como o compromisso do NuMI de oferecer a esta população as condições a seu alcance e no seu escopo de atuação que sejam favorecedoras destes processos, inclusive por meio de incubação. 


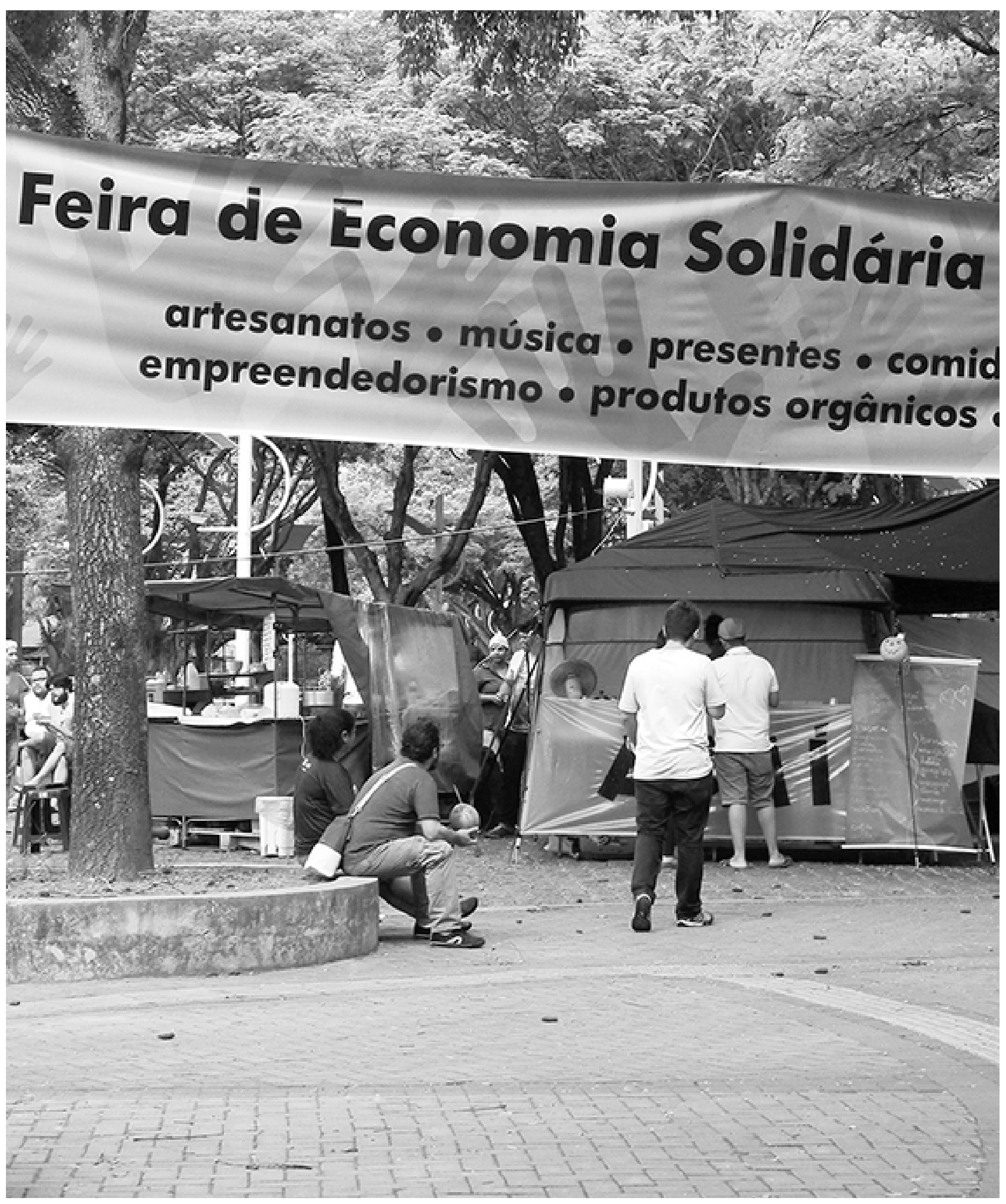


No entanto, as ações empreendidas pelo Numi-Ecosol são condicionadas tanto em sua abrangência quanto em seu escopo pela disponibilidade de financiamento, sendo uma pequena parte destes derivada do orçamento da própria Universidade, suficientes apenas para garantir o funcionamento mínimo de sua estrutura operacional. Todas as ações de fomento acima mencionadas dependem de recursos captados a partir de projetos específicos, os quais concorrem por recursos públicos a partir da abertura de editais (periódicos ou mesmo eventuais) por parte de diferentes órgãos governamentais. Fontes alternativas de financiamento, não governamentais, costumam ser escassas -ou inadequadas aos objetivos e valores da ES. Em função disso, as políticas públicas representam um papel central no que diz respeito às possibilidades $e$ limites de atuação do NuMl e de praticamente todas as incubadoras de empreendimentos econômicos solidários em todo o Brasil, trazendo à tona uma necessária reflexão sobre a relação - nem sempre harmônica - entre o movimento da ES e o poder público. Tal relação é permeada por diferentes visões sobre o fenômeno da ES, dentro e fora do governo.

São apresentadas a seguir algumas considerações sobre aspectos relacionados à interação entre o poder público e os apoiadores da economia solidária, que incluem uma descrição das principais políticas públicas de apoio e fomento atualmente registradas e dos segmentos sociais que costumam figurar como público-alvo das mesmas, e a indicação de algumas lacunas e elementos problemáticos destas políticas, com especial ênfase na experiência vivenciada em São Carlos e região.

\section{Economia Solidária e Políticas Públicas}

No Brasil, o apoio a iniciativas de ES por parte do poder público toca em algumas questões, relacionadas ao caráter atribuído a estas iniciativas e à definição do perfil de seus integrantes.

Em relação ao caráter atribuído, hoje podem ser identificadas duas visões antagônicas: para alguns, elas seriam potencialmente revolucionárias, capazes de minar as bases do próprio capitalismo (Singer, 2003), enquanto para outros não passariam de estratégias paliativas, especialmente úteis na acomodação dos segmentos marginalizados nestas sociedades, criando uma ilusão de autonomia entre seus adeptos sem, no entanto, confrontar a lógica do próprio sistema capitalista (Germer, 2006).

No entanto, em meio a este antagonismo cabe um amplo espectro de defensores da ES que não a concebem como algo necessariamente comprometido com a revolução, tão pouco com o conformismo: as iniciativas econômicas solidárias seriam, sim, pautadas por ideais de autogestão econômica, autonomia social e protagonismo político, mas sem que algum destes ideais esteja automaticamente imbuído de um caráter subversivo, muito menos subserviente (Gaiger, 2003). Em outros termos: se um dos princípios fundamentais da
ES é contribuir para que grupos e indivíduos sejam efetivamente protagonistas de seu destino, é razoável que caiba a estes a definição do caráter de suas ações, sem a imposição, a priori, de certas visões de mundo e trajetórias a elas atreladas. Desta forma, o fortalecimento da ES estaria mais relacionado à prática cotidiana dos ideais acima mencionados (autogestão, autonomia...) do que com resultados ou metas objetivas a serem atingidas (mensuráveis por meio de índices e taxas, como a redução da pobreza, a ampliação da participação nos mercados, etc.). É precisamente neste ponto que reside um dos problemas envolvendo a promoção da ES pela via das políticas públicas, como veremos mais adiante (França Filho, 2006).

Já em relação à definição do perfil de seus integrantes, menos do que tentar delimitar segmentos específicos a serem tratados como "público -alvo" da ES, aqui a questão passa mais pela necessária distinção entre esta "outra economia" e um certo cooperativismo cuja imagem -ainda muito presente entre os brasileiros- está associada a uma estratégia patronal de redução de custos, sempre em nome da competitividade mercadológica. A esta confusão entre uma coisa e outra pode ser acrescentado o preconceito de alguns (juristas, sindicalistas, acadêmicos) que enxergam no cooperativismo associado a segmentos populares tão somente uma tática empresarial para burlar a legislação trabalhista. Diferentes possibilidades de interpretação sobre o que é (e o que não é) ES acabam orientando políticas públicas de caráter diferenciado, dependendo do setor ou agente governamental responsável por sua implementação em nível local: em São Carlos, por exemplo (aonde está o NuMI-EcoSol, da UFSCar), o apoio da prefeitura se dá a partir da Secretaria do Trabalho, fazendo com que a EcoSol seja tomada majoritariamente como uma das estratégias voltadas para a "geração de emprego e renda", e neste sentido o apoio a empreendimentos econômicos solidários via incubadora municipal caminha lado a lado com o fomento ao micro empreendedorismo individual, com a organização de feiras locais, com os diagnósticos sobre cadeias produtivas etc. -sempre com um viés mais voltado para a "produção". Já em Rio Claro, cidade de porte equivalente localizada cerca de $60 \mathrm{~km}$ de São Carlos, o apoio à EcoSol por parte do poder público se dá pela Secretaria de Assistência Social: ali os empreendimentos solidários tendem a ser tratados muito mais como uma forma de promoção da cidadania, e em geral atuam junto segmentos vulneráveis da população, identificados a partir de cadastros utilizados pelo Ministério do Desenvolvimento Social, sendo a implementação de ações orientadas por um diagnóstico social de cada área ou bairro da cidade, com importante papel reservado para as entidades sociais (Mendes, Cortez e Ortigoza, 2013). Neste caso, o viés meramente produtivo cede um pouco mais de espaço para outro, mais focado na ação social, embora a natureza dos empreendimentos apoiados não fuja de um padrão registrado em escala nacional: reciclagem 
de lixo, artesanato, etc., como será melhor descrito mais adiante. Importante salientar que apesar das diferentes abordagens na escala local, as políticas públicas voltadas para a promoção da EcoSol estão articuladas a partir de uma secretaria nacional especialmente criada para este fim, a SENAES (Secretaria Nacional de Economia Solidária), que tem atuado por mais de dez anos -desde 2003- sempre no intuito de divulgar e apoiar a construção de "uma outra economia". Neste sentido, pode-se dizer que as diferentes interpretações sobre as possibilidades e os limites da ES têm sido evidenciados a partir do processo de negociação, mediado pela SENAES em espaços como o Fórum Nacional e o Conselho Nacional (de EcoSol) cujo foco se concentra na proposição de políticas públicas a serem levadas a cabo a partir da esfera nacional. Estes espaços deliberativos colocam, de um lado, o movimento (bastante plural) de economia solidária, e de outro, os interesses e resistências de diferentes segmentos do governo.

O próximo tópico visa destacar alguns elementos presentes neste processo, a partir da descrição sumária das principais políticas públicas voltadas para a EcoSol (das efetivamente implementadas até aquelas que permanecem "interditadas"), tornando possível a identificação dos principais elementos de tensão em torno do caráter das políticas públicas a serem construídas, bem como dos principais segmentos sociais que as reivindicam ou simplesmente as apoiam, em escala nacional.

\section{Entre diferentes formas de fomento e múltiplos atores}

As diferentes formas de fomento à EcoSol passam por pelo menos duas frentes importantes: 0 apoio à constituição de EES e a criação de espaço para a sua atuação. Entre as políticas correspondentes à primeira, podem ser destacadas:

- o Programa de Apoio às incubadoras de EES, identificado pela sigla PRONINC, vinculado à própria SENAES;

- parte das ações financiáveis pelo Programa de Extensão Universitária (PROEXT), vinculado ao Ministério da Educação; - constituição de um Fundo Nacional de Economia Solidária, gerenciado pela SENAES e que administra repasses para outras esferas administrativas (estados e municípios).

Tais políticas são as que contam com maior visibilidade, pois são estruturantes para toda a rede de apoio que atua em todo o território nacional, formada pelas incubadoras universitárias (fundamentalmente custeadas pelos editais do PRONINC e do PROEXT) e por incubadoras municipais e outros apoiadores financiados via Fundo Nacional. Cabe ressaltar que o repasse dos recursos federais é condicionado à criação de conselhos estaduais e municipais de EcoSol, responsáveis pelo gerenciamento local dos recursos repassados. Não obstante os recursos do Fundo Nacional possam ser utilizados para o provimento de apoio logístico e físico aos empreendimentos vinculados aos conselhos municipais, sua utilização costuma recair em gastos com formação e capacitação. Outra forma de apoio aos EES -mas ainda pouco presente- seria por meio de políticas direcionadas de crédito, particularmente importantes tendo-se em vista a exclusão destes do sistema bancário tradicional. Neste caso, o crédito poderia ser distribuído pela própria rede de bancos comunitários atualmente existente no país, emuma estratégia que incorpore este segmento da EcoSol no apoio aos demais. No entanto, não há uma política de financiamento público específico para EES (seja via bancos comunitários ou não), e mesmo as diferentes iniciativas de microcrédito registradas no país raramente extrapolam a esfera municipal ou se constituem de forma mais perene, ainda que a ampliação do acesso ao crédito tenha sido tratada como prioridade a partir do governo Lula (Barone e Sader, 2008). Até o presente momento, não há sinais de um programa creditício de dimensão nacional voltado exclusivamente para a EcoSol (Praxedes, 2009), a exemplo dos que já existem voltados para micro e pequenas empresas (Proger, Crediamigo) ou até para a agricultura familiar (PRONAF, Agroamigo) Uma questão frequentemente levantada pelos apoiadores que atuam em incubadoras - principalmente às vinculadas a universidades - diz respeito ao conteúdo dos editais (tanto PRONINC quanto PROEXT): por serem estes o resultado de um arranjo no qual diferentes ministérios federais aportam recursos, o papel reservado à ES passa a estar acomodado aos interesses específicos da cada área de atuação governamental. Desta forma, para muitos críticos, não existe realmente uma política pública de apoio à EcoSol, e sim um espaço de atuação reservado a ela dentro das políticas públicas voltadas para diferentes áreas, como a promoção da saúde, o desenvolvimento agrário, a assistência social, a gestão urbana, etc. Em termos teóricos, o fomento aos EES se configuraria como uma solução para diferentes problemas enfrentados pelo poder público... Uma "solução à espera de problemas", para usar a expressão oriunda do modelo "garbage can" (Cohen, Marsh e Olsen, 1972), sobre a própria natureza das políticas públicas desde uma perspectiva organizacional. Esta percepção de que a EcoSol seria fundamentalmente uma estratégia para se alcançar objetivos diversos, conforme prioridades desta ou daquela área governamental, é reforçada a partir de exemplos como o mencionado anteriormente em torno das cidades de São Carlos e Rio Claro, nos quais a secretaria que abriga o conselho de EcoSol local acabaria por informar o enfoque a ser privilegiado pelos EES de cada município. No entanto, em que medida isso seria inevitável e em que medida isso seria indesejável são indagações que permanecem em aberto, mas notavelmente recorrentes. Outra questão, desta vez envolvendo o interesse dos gestores públicos -de qualquer área- e os anseios de quem atua junto à ES, reside na importância dada aos resultados alcançados (ou 


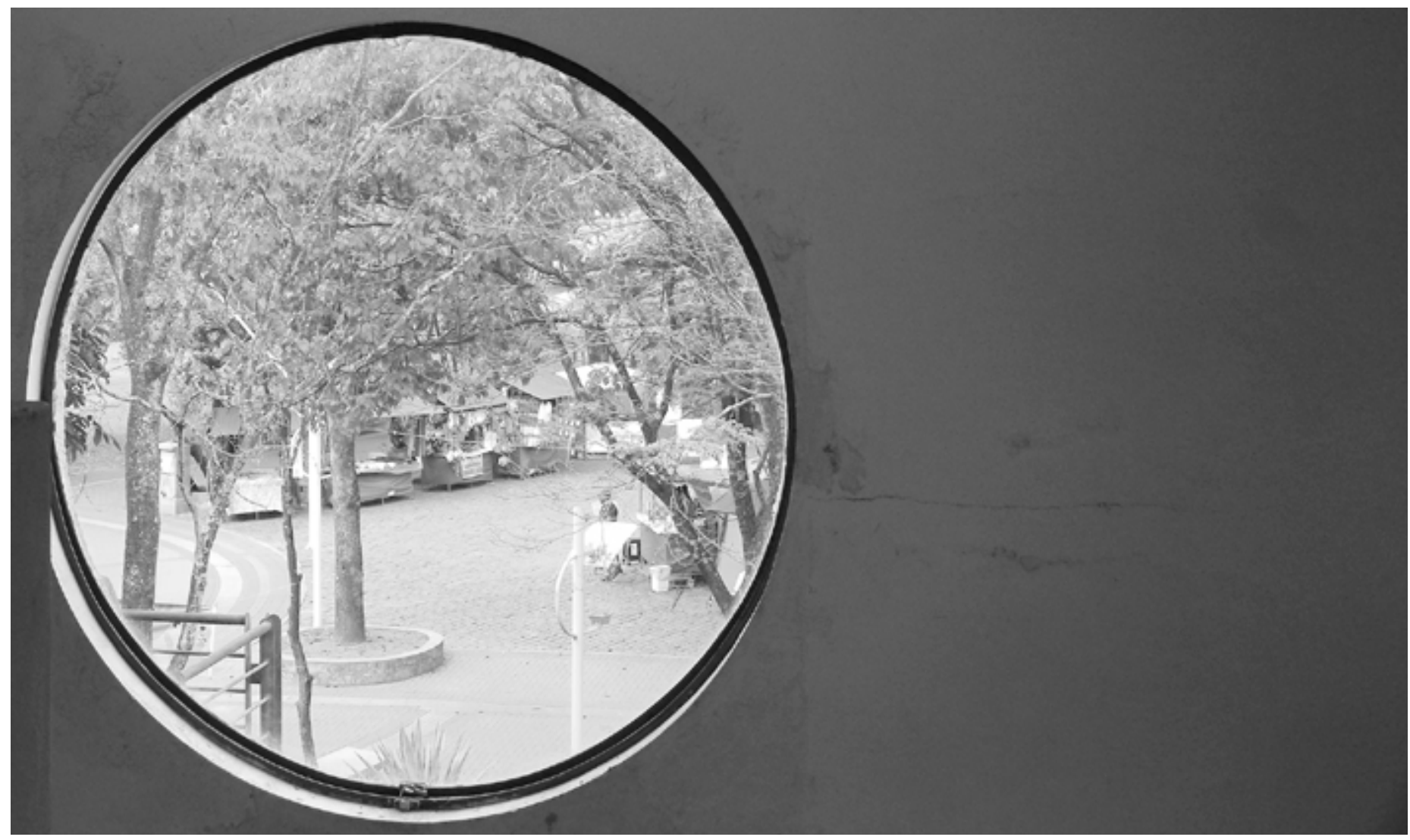

proporcionados) pelos EES, bem como nos indicadores utilizados para mensurá-lo. Se a EcoSol é vista como um meio para se atingir fins específicos, conforme a área de governo envolvida (e admitindose esta visão como muito comum entre os gestores públicos), a avaliação do sucesso ou fracasso das estratégias apoiadas (a EcoSol inclusa) parte logicamente de uma série de indicadores "emprestados" desta mesma área de governo...mas que raramente coincidem com os elementos considerados essenciais para avaliar um EES: democracia interna, autonomia do grupo, compartilhamento de responsabilidades, etc. -todos relacionados mais ao processo em si do que a resultados quantificáveis.

Este desencontro entre os indicadores de resultado, tão caros aos gestores públicos, e a prática cotidiana de acompanhamento por parte das incubadoras, acaba por impor aos fomentadores da EcoSol a missão ingrata de legitimá-la perante seus financiadores como algo "útil”, capaz de proporcionar o cumprimento de certas metas sociais ou econômicas de forma eficaz. Vale assinalar que tal desencontro figura como elemento particularmente problemático quando se discute sobre os benefícios trazidos por uma eventual política de crédito voltada para os EES e a tendência de que a mesma viesse a ser avaliada a partir de indicadores consagrados pelo sistema bancário tradicional.
Estes pontos evidenciam a tensão entre as inúmeras expectativas e a lógica essencial da Economia Solidária, à medida que o indispensável apoio do poder público a inúmeras iniciativas econômicas solidárias parece estar condicionado à resolução de problemas que não são realmente o foco essencial destas iniciativas. Noutros termos: os apoiadores não compreendem a natureza dos apoiados. E isso tende a gerar alguma frustração para ambos. No que diz respeito à segunda frente mencionada - a criação de espaço para a EcoSol, algumas iniciativas são particularmente importantes:

- A luta pela implementação de leis mais favoráveis a iniciativas econômicas de caráter solidário - seja pela via de sua desoneração tributária, seja pela descriminalização dos empreendimentos prestadores de serviço, ou mesmo por meio da viabilização de sua participação em processos de licitação de compras ou contratação de serviços por parte do poder público.

- Os chamados mercados institucionais, como o PAA -Programa de Aquisição de Alimentos do governo federal-, ou a parcela do PNAE -Programa Nacional de Alimentação Escolar- que é reservada (30 \% dos recursos disponíveis) ao segmento da Agricultura Familiar, além da promoção, no âmbito dos municípios, de feiras destinadas à comercialização de produtos oriundos de EES ou da Agricultura 
Familiar (tratando-se frequentemente de um público comum); Nestes casos, o que se entende por estratégias de fomento à EcoSol extrapola a noção simples de incubação, o que, sem dúvida, representa um avanço. Porém, a abertura de mercados a partir de compras ou contratação de serviços por parte do poder público traz resultados ambíguos para os EES: se por um lado a estratégia garante sua sobrevivência econômica (ao menos no primeiro momento) e cria bases para o crescimento de suas atividades, por outro lado os tornam dependentes do contrato (ou programa) que os beneficia, ao desestimular a exploração de outras possibilidades de inserção junto ao público em geral. Isso pode resultar em sérias crises advindas de mudanças de governo (quando contratos ou mesmo programas públicos inteiros podem ser descontinuados), revelando uma situação de vulnerabilidade por parte dos EES (Moya, 2013).

Pior do que isso: iniciativas alimentadas por contratos junto ao poder público ou voltadas para o fornecimento a mercados institucionais costumam ter especial dificuldade em se desenvolver de forma autônoma, muitas vezes por estarem sujeitas à ingerência de burocratas que passam a atuar como "patrões", outras vezes por serem vistas por muitos de seus participantes - sobretudo quando há um crescimento muito rápido em seu número -como um "emprego disfarçado" (o que se evidencia por ações trabalhistas empreendidas junto ao EES após a saída destes mesmos trabalhadores)- mas sobretudo pelo fato de que em muitos casos, a própria constituição do empreendimento não se dá de forma espontânea, e sim por iniciativa de pessoas ligadas à prefeitura ou simplesmente como estratégia voltada para a captura de recursos públicos (caso especialmente comum entre associações de agricultores cujo único objetivo é fornecer para programas como o PAA).

Diante do rol de políticas acima descritas, já é possível, com alguma facilidade, identificar os segmentos sociais que têm interesse pela ES: são os recicladores de lixo, articulados em torno de políticas urbanas desenvolvidas no âmbito do Ministério das Cidades - e para este segmento estão reservados espaços específicos nos editais federais que apoiam as atividades de extensão universitária (os PROEXT), entre outras possibilidades em outros editais específicos deste ministério; se no meio urbano a EcoSol está associada à reciclagem, no meio rural quem aposta no fomento aos EES e em estratégias voltadas para a comercialização de sua produção é o segmento dos agricultores familiares, sobretudo aqueles menos capitalizados e identificados com a agroecologia, e que têm recebido a atenção do Ministério do Desenvolvimento Agrário. Também neste caso, surgem linhas de financiamento específicas que associam EcoSol e Agricultura Familiar (inclusive os editais
PROEXT). Já entre os Ministérios da Saúde e do Desenvolvimento Social os segmentos "solidários" se identificam com os assim chamados grupos em desvantagem social-que incluem moradores de rua, pessoas comdistúrbios mentais, e dependentes químicossendo que aqui a EcoSol recebe claramente a incumbência de proporcionar a (re)inserção social de todos. $O$ artesanato e em alguma medida a reciclagem de lixo surgem como as "soluções" mais usuais. Algum interesse parte também das comunidades tradicionais, ribeirinhas ou caiçaras, seja a partir de iniciativas conservacionistas vinculadas ao Ministério do Meio Ambiente, seja pelo viés do trinômio turismo/artesanato/cultura, sendo este último termo mais recentemente vinculado também aos grupos genericamente identificados como jovens das periferias urbanas, frequentemente marcados pela violência (ou a ela associados, de forma estigmatizada). As áreas governamentais empenhadas em gerar respostas valendo-se mais uma vez da EcoSol seriam, nestes casos, o Ministério do Turismo e o da Cultura.

Não é de se estranhar que os segmentos acima elencados sejam evidentemente marginalizados em termos sociais, econômicos, políticos. Isso por si só indica que, aos olhos de um grande público já é clara a distinção entre o os EES e o setor cooperativista patronal, mencionado anteriormente. Mas tal distinção não define afirmativamente o que é a ES: esta parece ser melhor identificada por tudo o que ela não é, e isso se dá tanto no sentido de oposição (aos modelos empresariais capitalistas, ao agronegócio, etc.) quanto no sentido de associação (com a agroecologia, com o artesanato, etc.). Neste último caso, a economia solidária torna-se menos visível do que os próprios segmentos sociais que a reivindicam, o que pode explicar, ao menos em parte, a existência de políticas de crédito ou reservas de mercado para tais segmentos -a agricultura familiar é o exemplo mais óbvio- mas não exatamente para EES. Este viés de "negação" carrega certamente algumas qualidades, mas talvez torne menos viável a reversão do caráter residual das políticas públicas encarregadas de seu fomento.

Permanecem como desafios importantes, particularmente para as incubadoras de empreendimentos econômicos solidários, o avanço em termos de produção de conhecimento em relação a formas de fomento à constituição e consolidação destes empreendimentos, assim como as condições necessárias para a conservação e possibilidade de ampliação da economia solidária, como estratégia de enfrentamento da lógica capitalista e de construção de relações alternativas entre seres humanos e destes com seu ambiente. A diversificação e aprimoramento das ações de fomento, e o envolvimento de todos os atores da economia solidária com a construção de políticas públicas adequadas aos objetivos da economia solidária representam parte destes desafios. 


\section{Referências bibliográficas}

Barone, F. M. e Sader, E. (2008). Acesso ao crédito no Brasil: evolução e perspectivas. En Rev. Adm. Pública, 42 (6). Rio de Janeiro. Nov./Dec. disponível no portal Scielo: http://www.scielo.br/scielo.php?pid=\$0034-76122008000600012\&scrip$\mathrm{t}=$ sci_arttext

Bocayuva, P.C.C. (2001). Incubadora Tecnológica de Cooperativas Populares / COPPE/UFRJ. In Camarotti, I. e Spink, P. (orgs.), Redução da Pobreza e Dinâmicas Locais. Rio de Janeiro: editora FGV (Coleção FGV Prática).

Cohen, M.D.; March, J.G. and Olsen, J.P. (1972). Can Model of Organizational Choice. Administrative Science Quarterly, 17 (1), 1-25.

Cortegoso, A.L.; Shimbo, I.; Mezzacappa, G.G.; Pompermaier, H.M.; Godoy,

T.M.P. de (2011). Método de incubação de empreendimentos de trabalho coletivo na INCOOP/Universidade Federal de São Carlos: avanços e desafios em um contexto de desenvolvimento territorial com economia solidária. In Cortegoso, A.L.; Sarachu, G.; Pereyra, K. (orgs.), Prácticas Académicas Integrales em el Cono Sur. Colección temática PROCOAS - Universidad y Trabajo asociado, Volume 1. Montevidéo: Extensión Libros - UdelaR.

Cortegoso, A.L.; Pompermaier, H.M. (s/f). Método de atuação da INCOOP ao incubar empreendimentos solidários: descrição como forma de sistematização, construção de visibilidade e oportunidade para reflexão. In Cortegoso, A.L. e outros. Uma década de ensino, pesquisa e extensão em Economia Solidária na Universidade Federal de São Carlos: da INCOOP ao NuMI-EcoSol. No prelo.
Cruz, A. da (2011). A acumulação solidária - os desafios da economia associativa sob a mundialização do capital. In revista Cooperación \& Desarrollo, (99). 101-121. Bogotá: Indesco/UCC

França Filho, G. et al. (orgs.) (2006). Ação pública e economia solidária: uma perspectiva internacional (259-267). Porto Alegre: Ed. da UFRGS.

Gaiger, L.I.G. (2003). A economia solidária diante do modo de produção capitalista. Caderno CRH, (39), 181-211, jul./dez. Salvador.

Germer, C.M. (2006). A "economia solidária": uma crítica marxista. Em revista Outubro, (14), 193-214. São Paulo: Alameda.

Mendes, A.; Cortez, A.T. e Ortigoza, S. (2013). Desfazendo os nós do capital: território, ação social e economia solidária. Bauru: Canal 6.

Moya, R.D. (2013). Limites à Economia Solidária: legitimidade e legalidade. O caso da cooperativa Cooperlimp e seus impactos no desenvolvimento territorial. Dissertação de mestrado: PPGEU/UFSCar.

NuMI-EcoSol (2010). "Termo de Referência" do Núcleo Multidisciplinar e Integrado e Estudos, Formação e Intervenção em Economia Solidária-NUMI-EcoSol. São Carlos: UFSCar

Praxedes, S.F. (2009). Políticas Públicas de Economia Solidária: novas práticas, novas metodologias. IPEA: mercado de trabalho, (39), mai.

Singer, P. (2003). Economia solidária. En Cattani, A.D. (org.), A outra Economia. Porto Alegre: Veraz Editores. 